\title{
Author Correction: Predicting COVID 19 Spread in Pakistan using the SIR Model
}

\author{
Syed Tahir Ali Shah ${ }^{1}(\mathbb{D})$, Majad Mansoor ${ }^{2}$ (D) Adeel Feroz Mirza ${ }^{2 *}$ (D), \\ Muhammad Dilshad ${ }^{3}$ (D), Muhammad Imran Khan ${ }^{4 *}$ (D), Rahat Farwa ${ }^{5}$ (D), \\ Muhammad Ammar Khan ${ }^{6}$ (D), Muhammad Bilal' ${ }^{7}$ and Hafiz M.N. Iqbal ${ }^{8}$
}

${ }^{1}$ Iqra University Islamabad Sector H-9/1, Islamabad 45210, Pakistan.

${ }^{2}$ Department of Automation, University of Science and Technology of China, Hefei, Anhui, 230027, China. ${ }^{3}$ International Islamic University, Sector H-10, Islamabad 45210, Pakistan.

${ }^{4}$ Hefei National Lab for Physical Sciences at the Microscale and the Centers for Biomedical Engineering, University of Science and Technology of China, Hefei, Anhui 230027, China.

${ }^{5}$ Department of Gynaecology and Obstetrics, District Head Quarters Hospital Jhang 35200, Pakistan.

${ }^{6}$ Department of Gastroenterology and Hepatology Medicine, District Head Quarters Hospital Jhang 35200,

Pakistan.

${ }^{7}$ School of Life Science and Food Engineering, Huaiyin Institute of Technology, Huaian 223003, China.

${ }^{8}$ Tecnologico de Monterrey, School of Engineering and Sciences, Campus Monterrey, Ave. Eugenio Garza Sada 2501, Monterrey, N.L., CP 64849, Mexico.

*Correspondence: adeelferozmirza@gmail.com (AF Mirza) and imran_almani@yahoo.com (MI Khan).

Correction to: Journal of Pure and Applied Microbiology https://doi.org/10.22207/JPAM.14.2.40, published May 9, 2020.

The error has not been corrected in the PDF or HTML versions of the article.

*Correspondence: adeelferozmirza@gmail.com (AF Mirza) and imran_almani@yahoo.com (MI Khan)

Published: March 01, 2021

Citation: Shah STA, Mansoor M, Mirza AF, et al. Author Correction: Predicting COVID-19 Spread in Pakistan using the SIR Model. J Pure Appl Microbiol. 2021;15(1):462-463. doi:10.22207/JPAM.15.1.44

C The Author(s) 2021. Open Access. This article is distributed under the terms of the Creative Commons Attribution 4.0 International License which permits unrestricted use, sharing, distribution, and reproduction in any medium, provided you give appropriate credit to the original author(s) and the source, provide a link to the Creative Commons license, and indicate if changes were made. 
When revisiting the values of Beta, Gamma and $\mathrm{R}_{0}$ in our article, we the listed author(s) have found some errors and here we are pointing out some unintentionally leftover irregularities, typos and mistakes which should be corrected to justify and validate the values of Beta, Gamma and $R_{0}$, as per the differential equations. Hereby, we bring to your attention the following irregularities, typos, and mistakes in Table 2 Page $1426^{1}$.

In the original paper, the equations (given below 1 to 4 ) and Table 2 must read as:

The rate of susceptible people is calculated for a population using Eq. (1) and the description of the parameters is provided in Table $1^{1}$ :

$$
\frac{d(S)}{d(t)}=-\frac{\beta S I}{N}
$$

The Infection rate is calculated by Eq. (2)

$\frac{d(I)}{d(t)}=\frac{\beta S I}{N}-\gamma I$

The recovery rate is calculated by Eq. (3)

$$
\frac{d(R)}{d(t)}=\gamma I
$$

The death rate is calculated by Eq. (4)

$$
\frac{d(D)}{d(t)}=\frac{2 I}{100}
$$

\begin{tabular}{|c|c|c|c|c|c|c|c|c|c|c|c|}
\hline \multirow{3}{*}{ Cases } & \multirow{3}{*}{ Beta $(\beta)$} & \multirow{3}{*}{ Gamma $(\gamma)$} & \multicolumn{8}{|c|}{ Prediction with different Gamma $(\gamma)$ and Beta $(\beta)$ value } & \multirow[b]{3}{*}{$\mathrm{D}$} \\
\hline & & & \multirow{2}{*}{$\mathrm{R}_{0}$} & \multicolumn{3}{|c|}{ End of April } & \multirow[b]{2}{*}{$\mathrm{D}$} & \multicolumn{3}{|c|}{ End of May } & \\
\hline & & & & $\mathrm{S}$ & 1 & $\mathrm{R}$ & & $\mathrm{S}$ & 1 & $\mathrm{R}$ & \\
\hline Data 1 & 0.0892282 & 0.0584039 & 1.5277789 & 219977780 & 14553 & 7357 & 310 & 219911491 & 37275 & 50440 & 794 \\
\hline Data 2 & 0.0992282 & 0.078404 & 1.2656012 & 219977512 & 12656 & 9563 & 269 & 219923360 & 23960 & 52170 & 510 \\
\hline Data 4 & 0.0892282 & 0.078404 & 1.1380563 & 219978738 & 11700 & 9313 & 249 & 219940445 & 16327 & 42881 & 347 \\
\hline
\end{tabular}

Table 2. Prediction with different Gamma $(\gamma)$ and Beta $(\beta)$ value using SIRD Model

\section{References}

1. Shah STA, Mansoor M, Mirza AF, et al. Predicting COVID-19 Spread in Pakistan using the SIR Model. J Pure Appl Microbiol. 2020;14(2):1423-1430. doi:10.22207/JPAM.14.2.40 